\title{
The Impact of Islamic Based Accounting Education on Professional Conduct among Accountants: A Conceptual Review
}

\author{
Nor Azah Abdul Jalil', Hasnah Haron², and Muhammad Bin Muda ${ }^{3}$ \\ ${ }^{1}$ Cyberjaya Graduate School of Management and Finance, Universiti Islam Malaysia, Selangor, \\ Malaysia \\ ${ }^{2}$ Universiti Malaysia Pahang, Universiti Malaysia Pahang, Kuantan, Malaysia \\ ${ }^{3}$ Universiti Islam Malaysia, Universiti Islam Malaysia, Cyberjaya, Selangor, Malaysia
}

\section{Abstract}

The importance of developing a good curriculum for accountancy programs is due to the call of needs to ensure the safeguarding of the profession in the future. This paper tends to review the curriculum structure; emphasis on ethics and personal values (religiosity), which is presumed to have an impact on the conduct of accountants in their practice. Based on prior study, some ethics education programs have reported

Corresponding Author: Nor Azah Abdul Jalil azah@kuipsas.edu.my Hasnah Haron

hasnahharon@ump.edu.my

Received: 5 August 2019

Accepted: 14 August 2019

Published: 18 August 2019

Publishing services provided by Knowledge $E$

(C) Nor Azah Abdul Jali et al. This article is distributed under the terms of the Creative Commons Attribution License, which permits unrestricted use and redistribution provided that the original author and source are credited.

Selection and Peer-review under the responsibility of the FGIC2019 Conference Committee.

\section{G OPEN ACCESS} measurable success where it was found that ethics courses do improve students' ability to recognize ethical issues and had a higher level of moral reasoning abilities after taking ethics courses. This review hopes to add value to the existing literature on perceptions of ethics and personal values impact for accountants' behavior in their profession. Included in the review, are issued on the competency of the accountants.

\section{Introduction}

Many researchers have found interest due to the rising number of ethical conduct about financial reporting and accounting professional conducts whereby extensive discussions and solutions finding have been conducted to refrain ethical misconduct from continuing in accounting practice.

According to Yin Yin et al. (2014), ethics has already been included in the higher education curriculum. In line with the Malaysian National Higher Education System, the reassessment report on the accounting program at public universities (i.e., Hala Tuju 2006) stated that professional values and ethics should be embedded in all courses of the accounting program. It is hoped that by incorporating ethics into the courses, Malaysia can be perceived as one of the developing countries that are actively involved in the development of quality academic programs upon producing graduates who are knowledgeable and possess competencies that meet the requirements of the profession in line with the current and changing business environment. 
Attempts from industry are by addressing the issue through injecting religious and ethical elements. The existing codes of ethics focus on how professionals, including accountants, perform their functions. Such codes guide right and wrong and can serve as deterrents to the rationalization dimension of the fraud triangle.

Many universities have also introduced religiosity elements in their accounting curriculum (Muhamad et al., 2015), namely Islamic Science University Malaysia and International Islamic University Malaysia. However, the impact of these guidelines and curriculum are not well researched or documented.

It is the hope of this research will highlight some of the impacts that have been brought out from the guidelines and also the curriculum. Malaysia is serious about improving the quality of graduates especially accountancy talents produced by institutes of higher education as shown in The Malaysian Education Blueprint 2013 by The Ministry of Education Malaysia (Johari et al., 2016). Every student is expected to ensure they possess the knowledge, technical and leadership skills, bilingual proficiency, ethics, spirituality, and international identity. In line with that, a new released of Malaysian Education Blueprint 2015 - 2025 (Higher Education) also highlight ethics and spirituality as one of the graduates' attributes in order to balance the akhlaq (ethics) and ilmu (knowledge). The student is expected to have ethically and morally upright, spiritually grounded, compassionate and caring, appreciates sustainable development, and a healthy lifestyle.

The motivation to conduct this study came from the challenge faced by accountants today. In order to establish good ethical values, the existing curriculum should be enhanced by adding religiosity courses as to what being offered by the Islamic universities in Malaysia. The need to inculcate a strong base of ethics knowledge before practicing as an accountant.

\section{Research Problem}

The most important, yet most misunderstood, is the ethics in accounting, which concerns in the world of business today. Accounting ethics instruction has received a considerable amount of attention since the turn of the century. Enron's failure, Andersen's demise, KPMG's tax shelter scandal, and the 2008 financial crisis all caused additional scrutiny of the accounting profession. The resulting increased focus on accounting ethics has led to an examination of the ethical education provided to accounting students and calls for increased ethics coverage in colleges. Implications to the profession due to the 
scandals, deprived the integrity of the accounting reporting, reputation of the company, and tarnished the independence of accounting firms.

Several questions were asked by researchers in lieu of ethical failures in the accounting profession: how does the moral development of accountants and accounting students compare to those in other professions or other majors? Can ethics be taught to accounting students? What role should ethics play in the accounting curriculum? What types of accounting ethics education interventions are most effective?

Another concern over the profession is on the professional values obtained and later practiced by the accountants. Stephens et al. (2012) acknowledged that the values of those entering colleges are not up to the ethical demands of the accounting profession, but recognized the need for the high ethical standards demanded by the profession and the challenges that are faced by profession in recruiting individuals with high ethical standards.

The mission of the International Federation of Accountants (IFAC), as set out in its constitution, is to serve the public interest, strengthen the accountancy profession worldwide and contribute to the development of international economies. The International Accounting Education Standards Board (IAESB), has been established by the IFAC Board has been established to pursue this mission. The IAESB function is to develop and issue, in the public interest and under its authority, pronouncements including, International Education Standards (IESs), International Education Practice Statements (IEPSS), Information Papers and other information documents on pre-qualification education and training of professional accountants and continuing professional education and development for members of the accounting profession. Education consists of learning processes that are systematic, structured, and often formal and also includes a form of a developmental process referred to as training.

Values provide a basis for understanding the ethical decision-making process. Rokeach defines fundamental human values "as enduring beliefs regarding personally and socially preferable specific modes of conduct or ends states of existence." As an example, an individual who values equality will generally prefer equal rights to harmful discrimination. Each individual has an enduring set or cluster of rank-ordered (in terms of importance) values, referred to as a value system.

One of the essential aspects of the intellectual development of an accountant is the underlying philosophy in the education level received during their study. Bloom's taxonomy has been widely employed to achieve this aspect, and it seems, has considerable intuitive appeal in aiding initial conceptualization of educational objectives. The measurement of the accountants' professional conduct is another aspect of the 
importance to gauge whether the accountants are practicing in accordance with the standards set.

According to Stephenson (2016), ethical conduct can be developed based on how they understand their knowledge impact towards modifying and changing their behavior as long as having the opportunity to reflect and make a value judgment. The imposition of personal values into the curriculum, which includes all the elements in personal life code, humanistic belief and others could be the answer in refraining continuous corporate scandals from happening.

\section{Research Objectives}

This study aims to focus on the following objectives:

1. To examine the current accounting curriculum and requirements issued by the International Federation of Accountants [Code of ethics for professional accountants-2006] and recommendations highlighted by the Committee to Strengthen the Accountancy Profession report [2014] with emphasis on professional values and ethics and religiosity.

2. To explain how the professional values in accounting curriculum content and religiosity contribute to enhance the professional conduct of accountants.

\section{Literature Review}

The major aim of education theory is to enable the change of behavior to its pupil. The important gist is to guide human beings into being an individual with knowledge and wisdom and consequently transform their low ethical values initially instilled to higher ethical values which will lead to better conduct in their profession.

Massive amount of literature was found on whether ethics should be incorporated into the curriculum over recent decades.

The argument is that, if potential accountants are well-trained so that good values are inculcated, they could bring along such values to their professional lives; hence, practice ethical behavior. It is based on this understanding that criticisms have been leveled at educators for contributing to the corporate reporting scandals by discharging poor quality professional education. According to Amernic and Craig, "one of the causes of the seemingly never-ending parade of accounting scandals and unexpected company collapses is the inadequacy of university curriculum and business education." 
The domination of the learning techniques and rules has been the main objective and learning outcome in an accounting program thus leaving very little attention to instill values, ethics, and a sense of integrity in the process of teaching and learning. Additionally, Glover and Aono highlight the defects in the education system as being responsible for the behavioral problem of lack of ethics, which, in turn, has led to accounting fraud.

Therefore, the role of accounting education has risen in importance as a means to inculcate good behavior among accountants to complement the regulatory measure. Ethics in accounting education need to start with values, not codes of professional conduct and on responsibilities, not the rules.

\section{Ethics in Accounting Education}

Throughout any accounting courses, it is complimentary if some form of ethical modules were made compulsory for the students. Why is this so? As is known to all, education gives knowledge to an individual. Therefore, to produce an ethical accountant, the education has to provide for morality to be inculcated within an individual. This is what Huss and Patterson (1993) also noted in their paper 'Ethics in Accounting: Values Education without Indoctrination'. As highlighted in their paper, there are seven objectives to be fulfilled when ethics and accounting are integrated: (1) relate the accounting with the ethical issues, (2) recognize issues with ethical implications in accounting, (3) develop a sense of responsibility, (4) develop the abilities needed to deal with ethical dilemmas, (5) learn to deal with uncertainties, (6) ability to alter ethical behavior and (7) understand the relationship of accounting ethics with the general ethics field.

From the side of academicians, they should only present the ethical dilemmas to students and allow them to come up with their potential solution. They should not persuade students of their solutions. Different ideas are brought forward from different students would trigger much room for improvement to make a better ethical decision. In recent publications, it was highlighted that merely identifying the presence of an ethical situation is not enough. This is because once they have identified and made their own ethical decision, they are hesitant to voice it out. This is due to the belief that others hold the opposite opinion on the matter, and that is the right one. In simplicity, they are in favor of a 'perceived opinion' to which everyone might oppose. The term pluralistic ignorance is applied in this instance. Going along this line, the moral reasoning judgment of an individual is continually changing. 
Among accounting professionals, ethics education has attracted substantial interest given the notoriety of past high-profile corporate failures and scandals and their association with a lack of accountability and oversight. Prior research indicates the integration of ethics education in accounting programs has steadily expanded across different subjects/courses and in the type of teaching methods and support materials, e.g., lectures and tutorials incorporating textbook examples, in-class debates, real-life case analysis and journal/news article reviews.

On the other hand, Sugahara and Boland (2016) examine the teaching of ethics in the education system of Japan and found that its uniqueness particularly at the pre-qualification stage in tertiary schools where no formal or informal networks exist between accounting professional bodies and academics that foster the development of the accounting curriculum. As a result, ethics training is not included in the formal accounting education process nor is the completion of an ethics module a pre-requisite for attempting the Certified Public Accountants (CPA) examination in Japan. Instead, ethics training is only provided at the post-qualification stage through Continuous Professional Education (CPE) provided by the Japanese Institute of Certified Public Accountants ( JICPA, 1998).

\section{Code of Professional Ethics and Ethical Values in Accounting Courses}

According to IFAC (2008) the content of professional accounting education should consist of: (a) accounting, finance and related knowledge; (b) Organizational and business knowledge; and (c) Information technology knowledge and competencies. It is deemed that the professional knowledge component complements the non- professional knowledge, and the intellectual, personal, interpersonal, communication, and organizational and management skills developed in general education. Daniels (2011) explains that when professions and skills are made obsolete in the knowledge economy, the need for continued high-level lifelong learning becomes increasingly important to the sustainability and viability of local, regional, and national economies. This lifelong learning is often referred to as Executive and Professional Education (EPE). EPE consists of two primary areas - soft and functional skills. Technical and functional skills are acquired either at work or through formal training and education. However, soft skills or social, behavioral skills must be learned through understanding and practice.

Based on the growth of specialized certifications in today's world, it becomes clear that an important function of a certifying organization, in addition to certifying that 
a practitioner has the necessary competencies to meet a prescribed standard, is to transform or translate tacit knowledge into explicit and formalized knowledge. Most skills are developed after working through experimentation or under the authority of others.

Let take the audit as an illustration. Auditors need to possess skills that will help them meet the demands of the real-time economy. Audit education must catch up with the progress being made in the rest of the business world in order to maintain relevance. The traditional accounting education model tends to rely on knowledge of accounting concepts and rules. Audit education must shift students' attitudes, behavior, and objective knowledge. Putting these three dynamics at the core of an audit education program will prove immensely beneficial to the real-time economy auditors.

\section{Personal Values}

There are five assumptions underpinning Rokeach's conceptualization of values: (1) each individual possesses a relatively small number of values; (2) all people, everywhere, possess the same values but to different degrees; (3) values are organized into value systems; (4) personality, society, and its institutions, and culture are essential antecedents of values; and (5) the consequences of values are manifested in virtually all social phenomena. Values are viewed as both enduring yet changing for a lifetime. Addressing this apparent paradox, Rokeach argues that a change in values may be viewed as a reordering of priorities within a relatively stable value system. As a consequence, value systems are "... stable enough to reflect the fact of sameness and continuity of a unique personality socialized within a given culture and society, yet unstable enough to permit rearrangements of value priorities as a result of changes in culture, society, and personal experience." Values guide attitudes and act as imperatives to action. Values are to be distinguished from attitudes, with the latter relating to positive or negative evaluations of an object.

Values, on the other hand, are said to go beyond specific situations, potentially influencing a wide range of human behaviors, including motivating action and aiding in "the selection or evaluation of actions, policies, people, and events" (Schwartz, 2007, p. 1). It is perhaps not surprising, then, that values are seen as being inextricably linked to ethical decision-making processes. Kohlberg's cognitive development model, for example, conceptualizes values as a basis for ethical behavior. Likewise, Ferrell and Gresham's (1985) contingency model of ethical decision making includes individual values as an important prior presence of ethical behavior. Lan et al. (2008) consistently 
found with empirical evidence of certain value types being systematically associated with levels of moral reasoning among business undergraduate majors.

Personal values represent a potentially significant antecedent of ethical decision making. There is evidence that values may differ between students and practitioners. Lan et al. (2009), for instance, examined the personal value orientations (measured using Schwartz's (1992) 56 item Schwartz Value Questionnaire) of practitioners and students in China. Their sample included 454 practitioners from six large cities in China and 126 students who were enrolled in a graduate accounting program from a large university in central China. Both practitioners and students ranked Family Security, SelfRespect, Healthy and Honoring of Parents and Elders among their top four values, and Respect for Tradition, Authority, Detachment, Social Power, An Exciting Life, Devout, and Accepting My Portion in Life among the lowest seven values (although there were differences in the relative rankings of these individual values between the accountants and students). While there were similarities in values, the researchers also found 18 values that differed significantly between the two groups.

As a part of personal values, religiosity is viewed from a different perspective. It is believed to be inculcated to strengthen the syllabus of the ethics course, which can produce the most desired results, which is to produce accounting students who are ethically sensitive. Therefore, the ethical sensitivity of accounting students has to be studied on to add to the body of knowledge and help the academicians to come up with an accounting ethics syllabus which includes the elements that can produce students with high rationale of spiritual behavior and conduct upon their practice as an accountant. This is vital to develop the necessary skills to handle ethical dilemmas appropriately.

\section{Competency}

The National Education Law defines and classifies competencies by taking into account two big categories: professional competencies and transversal competencies. Professional competencies represent a unitary and dynamic ensemble of knowledge and abilities. Knowledge is expressed by the following descriptors: know-how, comprehension, and use of specific language, explaining, and interpretation. Abilities are expressed through the following descriptors: application, transfer, and problem-solving, critical and constructive reflection, creativity, and innovation. 
Transversal competencies are defined as being value acquisitions and the attitudes that surpass a particular study field/program and are expressed by the following descriptors: autonomy and responsibility, social interaction, personal and professional development (n.n. interesting is this separation of the competencies; I am for attaching creativity to this last type of competencies).

Professional competencies acquired in the students' learning process are always appreciated, but they might not be sufficient for getting hired, as some graduates from the accounting field might think at a given point. These kinds of situations may occur because there are companies which appreciate more the transversal competencies held by alumni, instruction at the workplace being the grounds which they build their human resources strategy.

For instance, Devonport found that, despite the efforts of many, a university degree has never been a prerequisite for membership of NZICA. In Australia, in the past, the two traditional professional accounting bodies (CPA Australia and Institute of Chartered Accountants in Australia) have for some time had fairly rigorous programs for qualification for entry to their membership. In the 1960s these bodies fought for a university degree prerequisite for membership. The success of this venture greatly assisted the establishment of accounting as a university discipline. However, as indicated above, a recent policy change by one of these bodies has done a great disservice to accounting as an intellectual endeavor. There is no qualified profession that does not require a university degree despite the high level of technical skills that some non-graduates may possess.

In the USA, to be a CPA requires university study amounting to 150 hours, which is usually well beyond a first degree. In the UK, there are many professional bodies, and for some, a university degree is not a necessity. They have argued, similar to the NZICA argument described by Devonport, that a rigors system of professional qualifying examinations can in most cases be taken to represent the equivalent of a first degree.

The International Federation of Accountants (IFAC), the international professional association of national accounting bodies, has for some time required its members to have programs of mandatory continuing education. If future professional accountants are to perceive professional values, ethics, and attitudes as relevant to their work, it is essential that they do not perceive the treatment of professional values, ethics, and attitudes as peripheral to their main education programs. 


\section{Conceptual Framework}

Based on all the literature discussed above, a conceptual framework is proposed based on the following hierarchy of importance;

i) introducing ethics courses in the Bachelor of Accountancy program together with the initial requirements by the International Education Standard and Code of Ethics for Professional Accountants,

ii) ensuring the quality of knowledge required is ample with emphasis on how to blend the professional values obtained from the standards together with personal values (morality, religiosity, culture, etc.) in order to enhance the professional conduct as an accountant by profession.

This model is supported by Utami (2011) which suggest that professional knowledge component complements the nonprofessional knowledge, and the intellectual, personal, interpersonal, communication, and organizational and management skills developed in general education.

Moreover, Stephenson's (2016) Reflective Ethical Decision Model (REDM) description highlighted the uses of philosophical humanism in collaboration with self-directed learning to help students determine and design their model construct of ethical values. The reason underpinning this idea is to evoke the personal ethics each of us has, not to promote additional avenues to extend the fallacy surrounding business ethics.

According to Stephenson, the rationale used in designing this model and developing this approach is the notion that operational values and orientations which guide human behavior are not fully developed until early adulthood. Accordingly, the author believes that students of all ages must be encouraged to develop their own personal ethics code of conduct even from an early age, and more importantly before they join a business or organization because these skills cannot be taught when they arrive.

\section{Research Questions}

Based on the discussion from a prior study, it can be stated that ethics and personal values (religiosity) courses do contribute to the accountants' professional conduct. This study intended to extend the discussion by looking at two perspectives; the graduates and the employer, which will enable the researcher to prove the sustainability of the ethics and personal values (religiosity) courses introduced during their undergraduate level do instill positive behavior in the graduates' professional conduct as an accountant. Therefore, the questions of this study are: 


\section{Conceptual Framework}

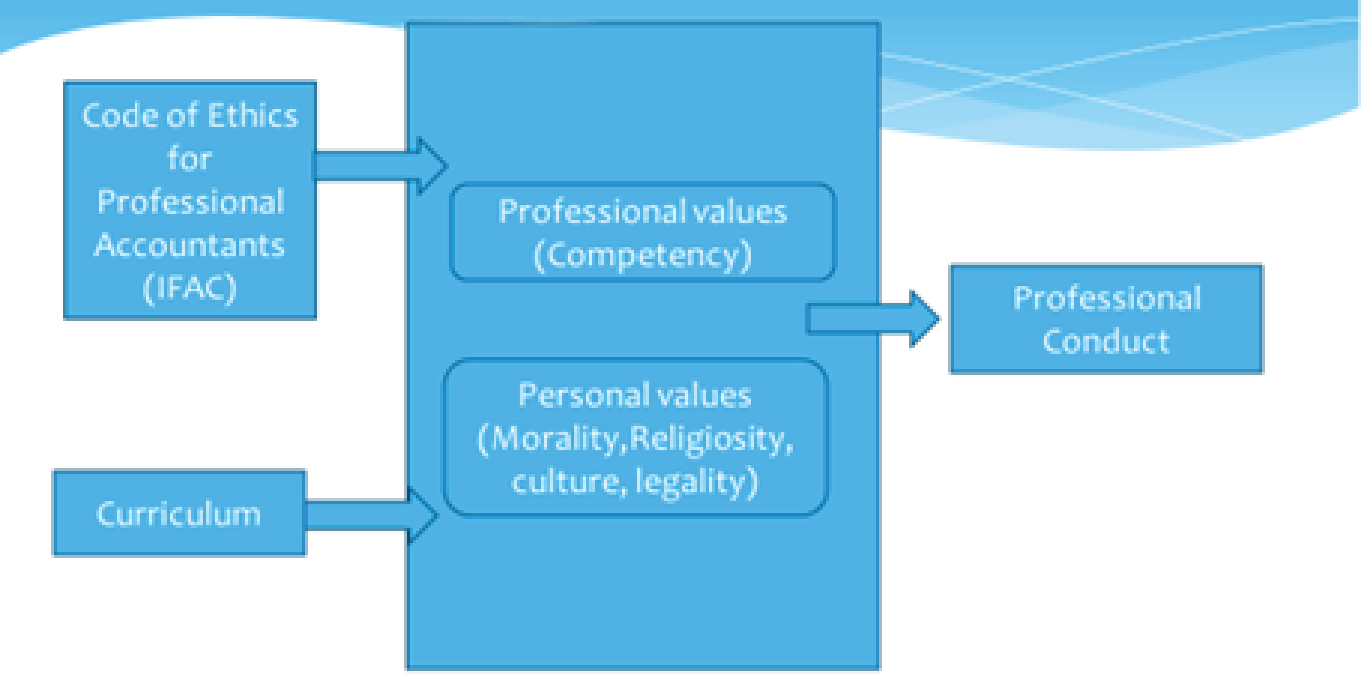

Source: Stephenson (2016) with adaptation

Figure 1: Conceptual Framework.

1. How do ethics as content in the curriculum affect the professional conduct of an accountant?

2. How does personal values (religiosity) in the accounting curriculum content contribute to enhance the professional conduct of accountants?

This study is exploratory research that uses a qualitative approach. The qualitative approach needs the researcher to collect a detailed database and use various methods to triangulate data and increase the reliability of the study. The potential participants of the research will be samples which could give in-depth information via interview sessions.

\section{Conclusion}

The purpose of this study is to explain how the professional values in accounting curriculum content and religiosity contribute to enhance the professional conduct of accountants. It is assumed that both elements will associate to a better conduct of accountants in their practice. It is hoped that this study will contribute to the number of works of literature on the importance of ethics and personal values (religiosity) as 
a content in the curriculum to enhance the professional conduct of accountants in the future.

\section{Acknowledgement}

We would like to thank Yayasan Bank Rakyat for the financial support by sponsoring this paper to be presented in the FGIC $2^{\text {nd }}$ Conference on Governance and Integrity 2019.

\section{References}

[1] Ahmad, N. (2015). Integrating ethics into accounting curriculum: Overview from Malaysian accounting educators. Malaysia Journal of Society and Space 11. Issue 6 (87 - 97)

[2] Blanthorne,

C. (2017).

Designing

a

Theme-Based Ethics

Course in Accounting. 135-140. https://doi.org/10.1108/S1085462220170000020006CodeofEthicsforProfessionalAccountants. 2016

[3] Dellaportas, S., Kanapathippillai, S., Khan, A. \& Leung, P. (2014). Ethics Education in the Australian Accounting Curriculum: A Longitudinal Study Examining hopes Enablers. Accounting Education: An International Journal.

[4] Fukofuka, S. (2007, October). The Impact of Spirituality on Academic Performance. International Forum. 10(2). 35-47

[5] Graham, A. (2012). The Teaching of Ethics in Undergraduate Accounting Programmes: The Students' Perspective. Accounting Education: an international journal. Vol. 21, No. 6, 599-613, December 2012

[6] Gray, R., Bebbington, J. \& McPhail, K. (1994). Teaching ethics in accounting and the ethics of accounting teaching: educating for immorality and a possible case for social and environmental accounting education. Accounting Education. 3(1). 51-75

[7] Hala Tuju 3-Laporan Penilaian Semula Program Perakaunan Institusi Pendidikan Tinggi 2013

[8] International Federation of Accountants. (IFAC). (2008). International education standards for professional accountants 4: Professional values ethics and attitudes. New York: IFAC

[9] Jackling, B. (2005, September). Perceptions of the Learning Context and Learning Approaches: Implications for Quality Learning Outcomes in Accounting. Accounting Education; an International Journal, 14(3). 271-291 
[10] Johari, N., Mustaffha, N., \& Mohd Deni, M.I. (2016). Integration of Islamic values in accounting education: Accounting academician perspectives. e-Jurnal Penyelidikan dan Inovasi. Vol. III, No. I (April 2016) 61 - 83

[11] Jones, G. \& Abraham, A. (2007). Education Implications of the Changing Role of Accountants: Perceptions of Practitioners, Academics and Students. University of Wollongong

[12] Kasim, N. \& Mohd Sanusi, Z. (2013). Emerging issues for auditing in Islamic Financial Institutions: Empirical evidence from Malaysia. IOSR Journal of Business and Management. Vol 8. Issue 5. 10-17

[13] Kelly, P.T. (2017). Integrating Leadership Topics into an Accounting Ethics course Preparing Students for a Challenging Profession. Advances in Accounting Education: Teaching and Curriculum Innovations. 141-180.

[14] Martinov-Bennie, N. \& Mladenovic, R. (2013). Investigation of the Impact of an Ethical Framework and an Integrated Ethics Education on Accounting Students' Ethical Sensitivity and Judgment. Journal of Business Ethics. 127(1) pp 189-203

[15] Marzuki,M., Subramaniam, N., Cooper, B.J. \& Dellaportas, S. (2017). Accounting academics' teaching self-efficacy and ethics integration in accounting courses: A Malaysian Study. Asian Review of Accounting. Vol 25. No 1. 148-170

[16] Mayhew, B.W. \& Murphy, P.R. (2009). The Impact of Ethics Education on Reporting Behavior. Journal of Business Ethics. 86:397-416

[17] Muhamad, H., Salleh, A., Ismail, H., \& Kasim, N. (2015). The need for ethics, learning objectives and the nature of content in existing accounting curriculum. Akademiabaru.Com, 9(1), 10-26

[18] Rodzalan, S.A. \& Saat, M.M. (2016). Ethics of Undergraduate Students: A Study in Malaysian Public Universities. International Journal of Information and Education Technology. Vol 6. No. 9. 672-678

[19] Singh, J., Hanefah, M.M. \& Kaur, K.. (2018). Journal of Governance and Integrity (JGI). Volume 2, Issue 1,91-132

[20] Sugahara, S \& Boland, G. (2016). Faculties' Perceptions of Ethics in the Accounting Curriculum: A Japanese Study. Research on Professional Responsibility and Ethics in Accounting. Vol 15. 193-224

[21] Stephenson, S.S. (2016). Reflective Ethical Decision: A Model for Ethics in Accounting Education. The Accounting Educators' Journal. Vol Special Edition. Pp 11-37

[22] The Report on the Strengthening of the Accounting Profession in Malaysia. 2015 
[23] Tweedie, D., Dyball, M.C., Hazelton, J. \& Wright, S. (2014). Teaching Global Ethical Standards: A Case and Strategy for Broadening the Accounting Ethics Curriculum. Journal of Business Ethics

[24] Utami, W. et al. (2011). Professional Accounting Education in Indonesia: Evidence on Competence and Professional Commitment. Asian Journal of Business and Accounting. 4(2). 93-118

[25] Yin, Y.W., Ismail, S. \& Abdul Hamid, F. (2014). Malaysian Accounting Educators' Perceptions on Ethics Education in the Accounting Curriculum. Malaysian Accounting Review. Vol 13 No 1 June 2014 